\title{
Comparative Electrochemical Noise Study of the Corrosion of Different Alloys Exposed to Chloride Media
}

\author{
Adham M. Nagiub \\ Department of Chemistry, Faculty of Science, Al-Azhar University, Assuit, Egypt \\ Email: Adham.nagiub@gmail.com \\ Received 2 September 2014; revised 6 October 2014; accepted 2 November 2014 \\ Copyright (C) 2014 by author and Scientific Research Publishing Inc. \\ This work is licensed under the Creative Commons Attribution International License (CC BY). \\ http://creativecommons.org/licenses/by/4.0/

(c) (i) Open Access

\begin{abstract}
This paper describes the corrosion behavior of aluminum, copper, and mild steel when exposed to chloride media using both electrochemical noise analysis (ENA) and electrochemical impedance spectroscopy (EIS). Analysis of electrochemical noise (EN) data demonstrated the need for removal of drifts in both potential and current fluctuations. Statistical analysis such as noise resistance, localization index, skewness and kurtosis has been evaluated. Noise resistance showed a good agreement with polarization resistance. Fast Fourier transformation (FFT) has been applied to convert EN data from the time domain to the frequency domain. Spectral noise plots showed a good agreement with impedance spectra for the different alloys determined at the same exposure time. Spectral and statistical analysis can extract useful information from EN data.
\end{abstract}

\section{Keywords}

Aluminum, Copper, Mild Steel, Electrochemical Noise, Electrochemical Impedance, Seawater

\section{Introduction}

Electrochemical noise is a general term for the random fluctuations in current or potential, which occur as an electrochemical process proceeds. The measurement of electrochemical noise (EN) for corrosion studies was first described by Iverson in 1968 [1]. At the same time Tyagai examined EN [2] [3]. First studies on EN were carried out using only one working electrode, and consequently this will not allow the measurement of corrosion rate. Eden et al introduced the use of cell with two identical working electrodes connected with a zero resistance ammeter (ZRA) so that it is possible to collect both the current and potential fluctuation simultaneously [4]. The using of two identical electrodes arrangement will allow obtaining the noise resistance (Zn), which is defined as 
the ratio of the standard deviation of the voltage and current fluctuations. Zn was compared to the polarization resistance (Zp) and many attempts had been done to compare Zn to Zp [5]-[9]. Zn was found to be close to Zp under certain conditions so that $\mathrm{Zn}$ can be used to calculate the corrosion rate using Stern-Geary relationship [10]. There are many advantages of EN as compared with the other electrochemical techniques making it very popular of these; the low cost of the equipment, ease of data collections and also EN is considered to be a time saving techniques (most experimental time ranged between few minutes to 1/2 hour). Electrochemical noise data can be analyzed in both time and the frequency domains. Recently, the validity of statistical parameters such as localization index (LI), skewness and kurtosis and frequency parameters such as power spectral density (PSD) slopes and spectral noise resistance $\left(Z_{s n}\right)$ obtained from analyzing the $\mathrm{EN}$ in the time and frequency domains have been discussed [11]-[13].

A theoretical and experimental analysis of the effects of trends in the potential and current noise fluctuations observed during measurement of EN data have been studied before [12]. It was found that the dc trend can affect the calculated values of the standard deviations of the potential and current fluctuations and $\mathrm{Zn}$ also the trends can affect the frequency dependence of the PSD plots at lower frequency and resulted in PSD slopes close to zero for both current and potential PSD plots. It was found that when a linear trend removal method was used, the noise plots and the impedance plots showed a very good agreement for mild steel/NaCl system [12]. The same findings were observed for brass exposed to $\mathrm{NaCl}$ with and without BTA. A good agreement was obtained between the noise plots and the impedance plots for brass exposed to $\mathrm{NaCl}$ with BTA after trend removal [13]. The present works aims to test the validity of electrochemical noise analysis in studying different alloys compared to electrochemical impedance spectroscopy.

\section{Measurements Methods}

The test solution was 3.5\% NaCl. Three different alloys have been selected for this study, mild steel 1018, aluminum 2024 and pure copper 99.9\%. These alloys will represent three different corrosion mechanisms when expose to $3.5 \% \mathrm{NaCl}$ solution. The exposed surface of the electrodes were polished with SiC paper up to 1200 grit, washed with distilled water and dried in air.

\subsection{Electrochemical Noise (EN)}

EN were performed in a set-up with electrochemical cell consisted of two identical working electrodes with an exposed area of $1.0 \mathrm{~cm}^{2}$ for each electrode and a saturated calomel electrode (SCE) as a reference electrode within a Faraday cage. An AutoCAD DSP device (ACM Instruments) was used to collect potential and current fluctuation simultaneously. Potential and current fluctuations were obtained, with a sampling rate of 2-point $\mathrm{s}^{-1}$ during a time period of 1024 seconds, which fixed the frequency range $(\Delta \mathrm{f})$ in region between $1 \mathrm{~Hz}$ and about 1 $\mathrm{mHz}$. The instrument noise was tested and shown to be with no influence on the noise measurements. A polynomial trend removal method was performed to remove the direct current (DC) drift contained in the noise data and a Hann window was applied before computing the PSD plots. The analysis of EN data in time and frequency domain was developed using Mathcad. The time-series data of the potential and current fluctuations were transformed into frequency domain by using the fast Fourier transformation (FFT) method.

\subsection{Electrochemical Impedance Spectroscopy (EIS)}

EIS measurements were made with AutoCAD DSP device (ACM Instruments) and by applying a sinusoidal voltage signal of $10 \mathrm{mV}$ over a wide frequency range of $10^{4}-10^{-3} \mathrm{~Hz}$ at open circuit potential (Ecorr) and room temperature.

\section{Results and Discussion}

The potential and current fluctuations were recorded simultaneously as described in the experimental section. Figure 1 shows the plots of the potential and current noise for copper exposed to 3.5\% $\mathrm{NaCl}$ for 1 day, both in time and frequency domains. As described elsewhere the DC trend will affect the estimation of noise parameters calculated both in time and frequency domains. The presence of the trend can mask the shape of current and potential fluctuations and may also affect the slopes of PSD plots of the current and potential [11]-[13].

Accordingly, polynomial trend removal method was applied to remove the DC trends in this study. EN data 
for copper exposed to $\mathrm{NaCl}$ for 1 day after removing the trend (de-trended data) are shown in Figure 2. Polynomial trend method is the preferred method in this study since the observed DC trend did not follow a specific pattern. It can be concluded that cautions should be taken during removing the trend when the DC trends did not follow a specific pattern.

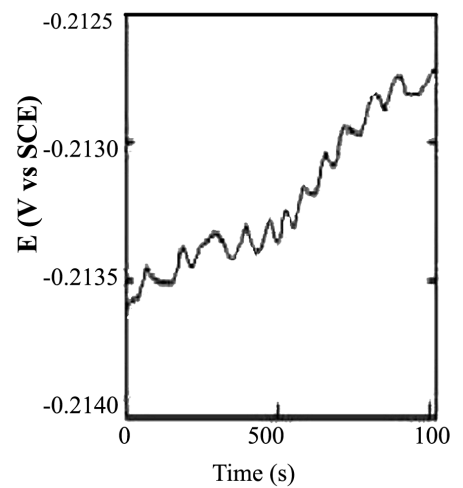

(a)

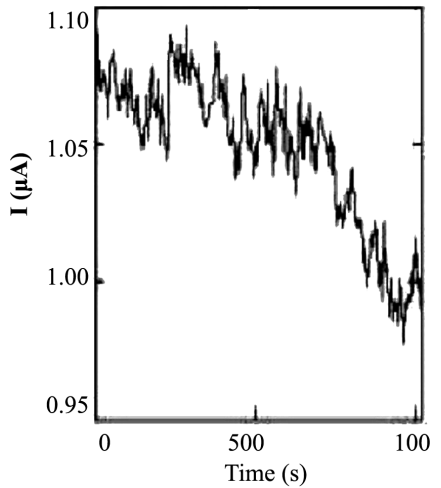

(b)

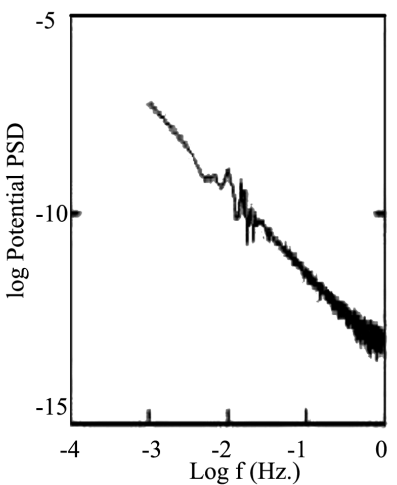

(c)

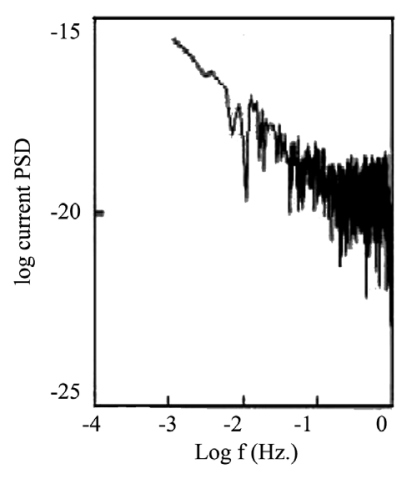

(d)

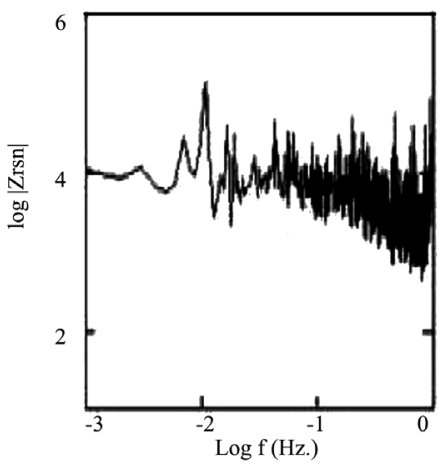

(e)

Figure 1. EN data in the time and frequency domain for copper exposed to $\mathrm{NaCl}$ for $1 \mathrm{~d}$.

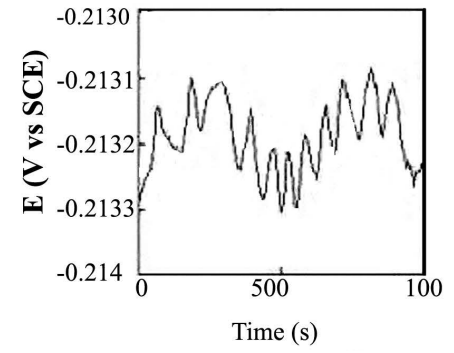

(a)

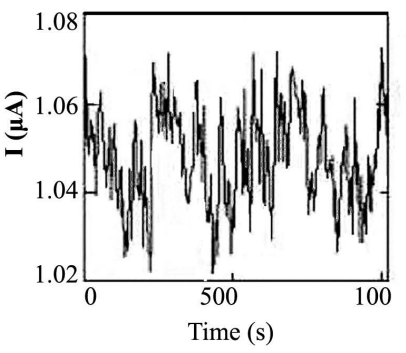

(b)

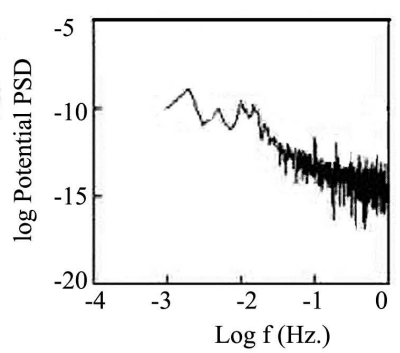

(c)

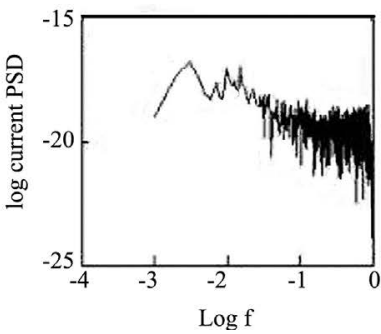

(d)

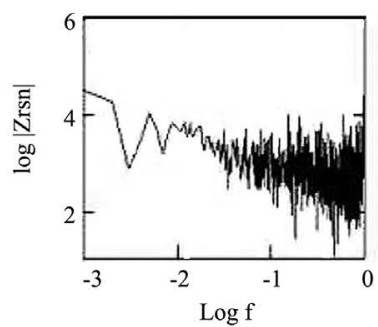

(e)

Figure 2. EN data in the time and frequency domain for copper exposed to $\mathrm{NaCl}$ for $1 \mathrm{~d}$ after trend removal. 
Noise resistance $(\mathrm{Zn}=\sigma \mathrm{V} / \sigma \mathrm{I})$ is defined as the ratio of the standard deviations of the potential fluctuations to the current fluctuations [5]-[9]. Figure 3 shows the time dependence of $\mathrm{Zn}$ for $\mathrm{Al} \mathrm{2024,} \mathrm{Cu}$ and MS 1018. It is obvious that the largest $\mathrm{Zn}$ values were obtained in case of aluminum. Values of Zn did not significantly change in case of $\mathrm{Al}$ which may be due to the formation of passive film over the exposed surface of aluminum that will protect the surface. On the other hand Zn decreased with increasing time for MS which was expected for uniform corrosion mechanism. Zn was slightly changed with time for Copper exposed to NaCl solution (Figure 3).

Eskew and Iskew are the skewness of the potential and current fluctuations, respectively, which describes the asymmetry of the probability distribution of the EN data. For a symmetric distribution the skewness will be zero, positive values indicate that the data are skewed to the right from the normal distribution, which means that the distribution is concentrated in its leftmost part with along thin tail to the right, while negative values mean that the distribution is skewed to the left. Ekurt and Ikurt are the kurtosis of the potential and current fluctuations, respectively, which is a measure of the shape of the ENA data. The kurtosis will be 3 for normal distribution for values larger than 3 the normal distribution will be sharply peaked and for values less than 3 it will be flatter. Skewness and kurtosis are calculated as [14]:

$$
\text { Skewness }=\frac{\frac{1}{N} \sum_{i=1}^{N}\left(x_{i}-\bar{x}\right)^{3}}{\sigma^{3}}, \text { Kurtosis }=\frac{\frac{1}{N} \sum_{i=1}^{N}\left(x_{i}-\bar{x}\right)^{4}}{\sigma^{4}}
$$

where $N$ is the number of points used. Figure 4 shows the time dependence of current skewness (Iskew) (Figure 4(a)) and potential skewness (Eskew) (Figure 4(b)) for $\mathrm{Al}, \mathrm{Cu}$ and $\mathrm{MS}$ exposed to $\mathrm{NaCl}$ with trend removal. After removing the dc trend skewness values were close to zero. Figure 4(c) and Figure 4(d) illustrate a comparison between kurtosis values obtained for the three tested alloys after removing the dc trend ,where Ekurt and Ikurt. Both kurtosis and skewness were independent of time. It was concluded that both kurtosis and skewness could only be used as an indicative of normal distribution of noise data, however not be used to suggest corrosion mechanism.

It has been assumed that LI values can be used to differentiate between types of corrosion, for example LI close to zero suggests general corrosion, while Il close to 1 corresponds to localized corrosion (9). The values obtained in this study indicate that Il cannot be used to differentiate between types of corrosion, which is in agreement with our previous results (14). It was concluded that Il could not be used to determine the corrosion mechanisms Figure 4(e) shows the comparison between localization index for $\mathrm{Al}$, $\mathrm{Cu}$ and MS when exposed to $\mathrm{NaCl}$ solution.

Figure 5 shows a comparison between the impedance spectra obtained for $\mathrm{Al}$, Cu and mild steel exposed to $\mathrm{NaCl}$ for 12 days. It is obvious that the shape of the impedance spectra is very characteristics for each alloy. As described elsewhere [14]-[16]. A localized mechanism was observed for Al, uniform corrosion mechanism for mild steel and a diffusion controlled mechanism could be suggested for copper. Impedance data were fitted according to the suitable equivalent circuit as described before [13]-[17].

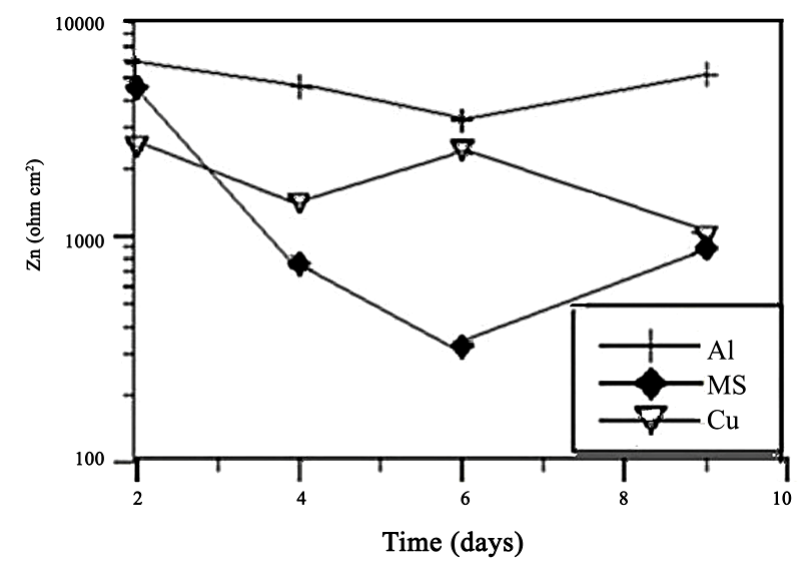

Figure 3. Time dependence of $\mathrm{Zn}$ for $\mathrm{Al} 2024$, MS 1018 and $\mathrm{Cu}$ alloys exposed to $3.5 \% \mathrm{NaCl}$. 
A. M. Nagiub

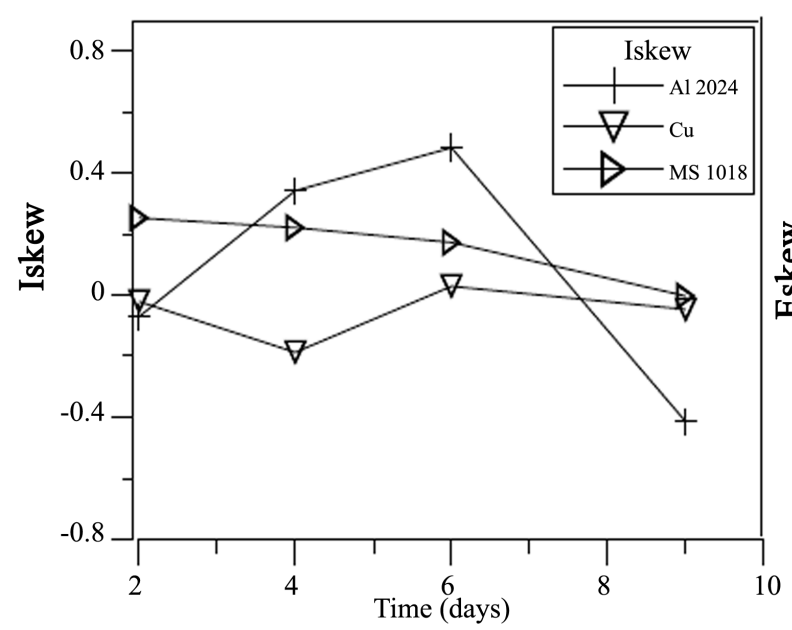

(a)

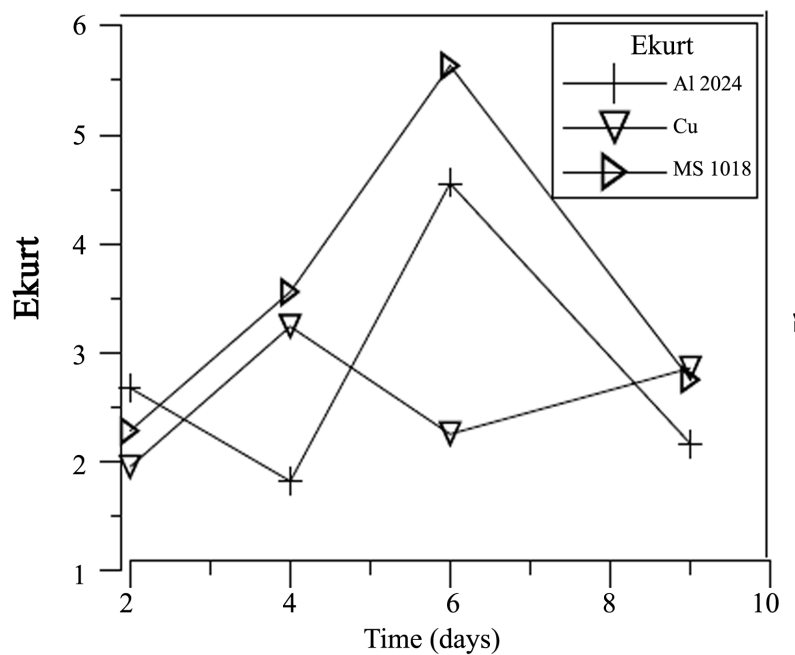

(c)

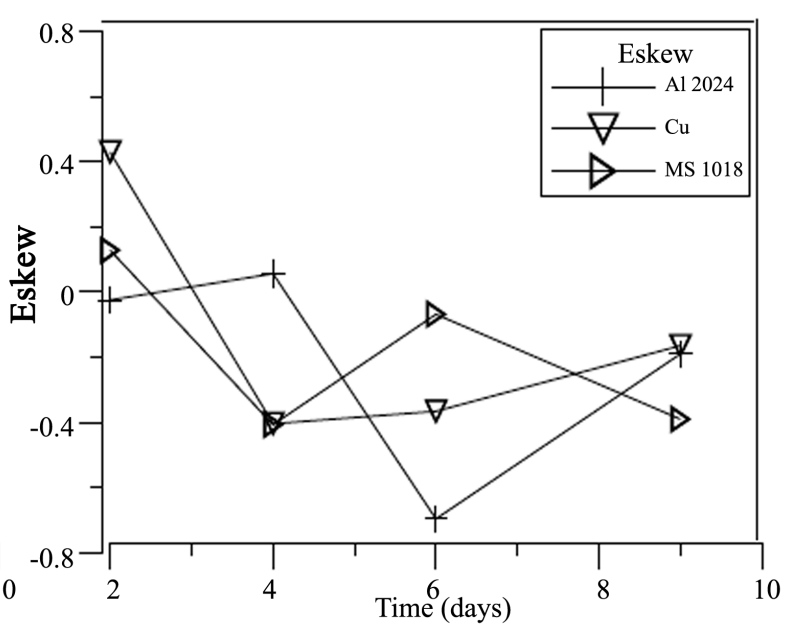

(b)

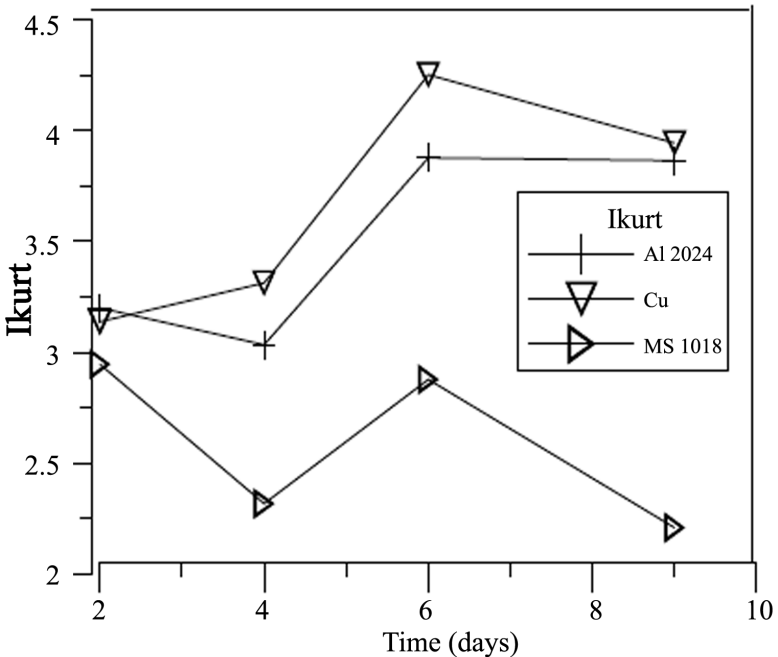

(d)
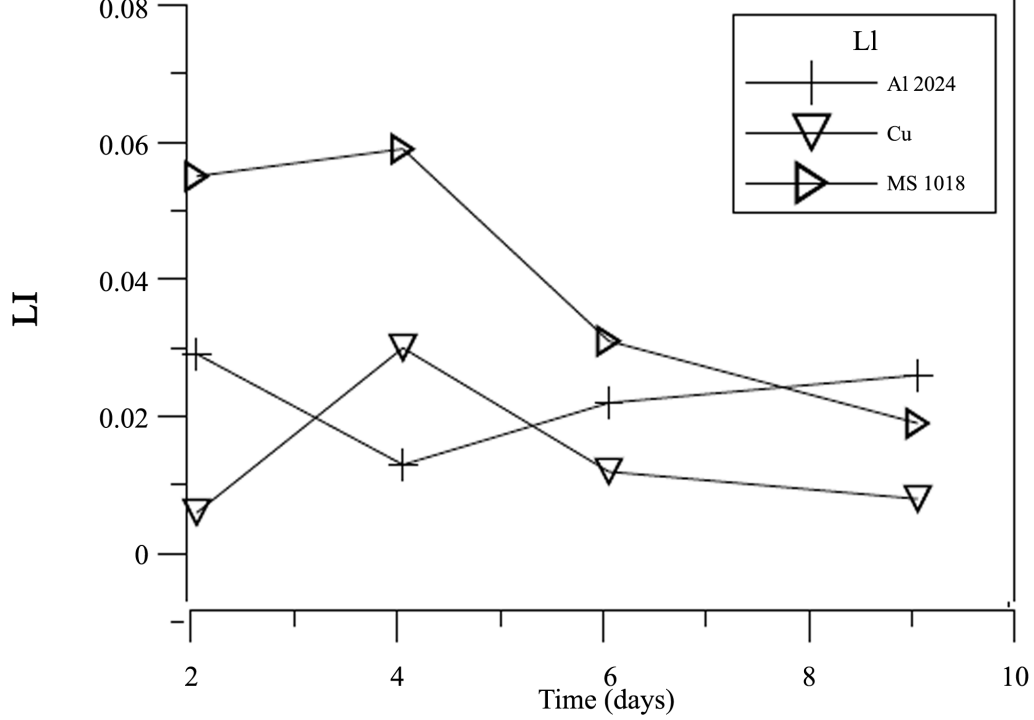

(e)

Figure 4. Time dependence for Kurtosis, skewness and LI. 

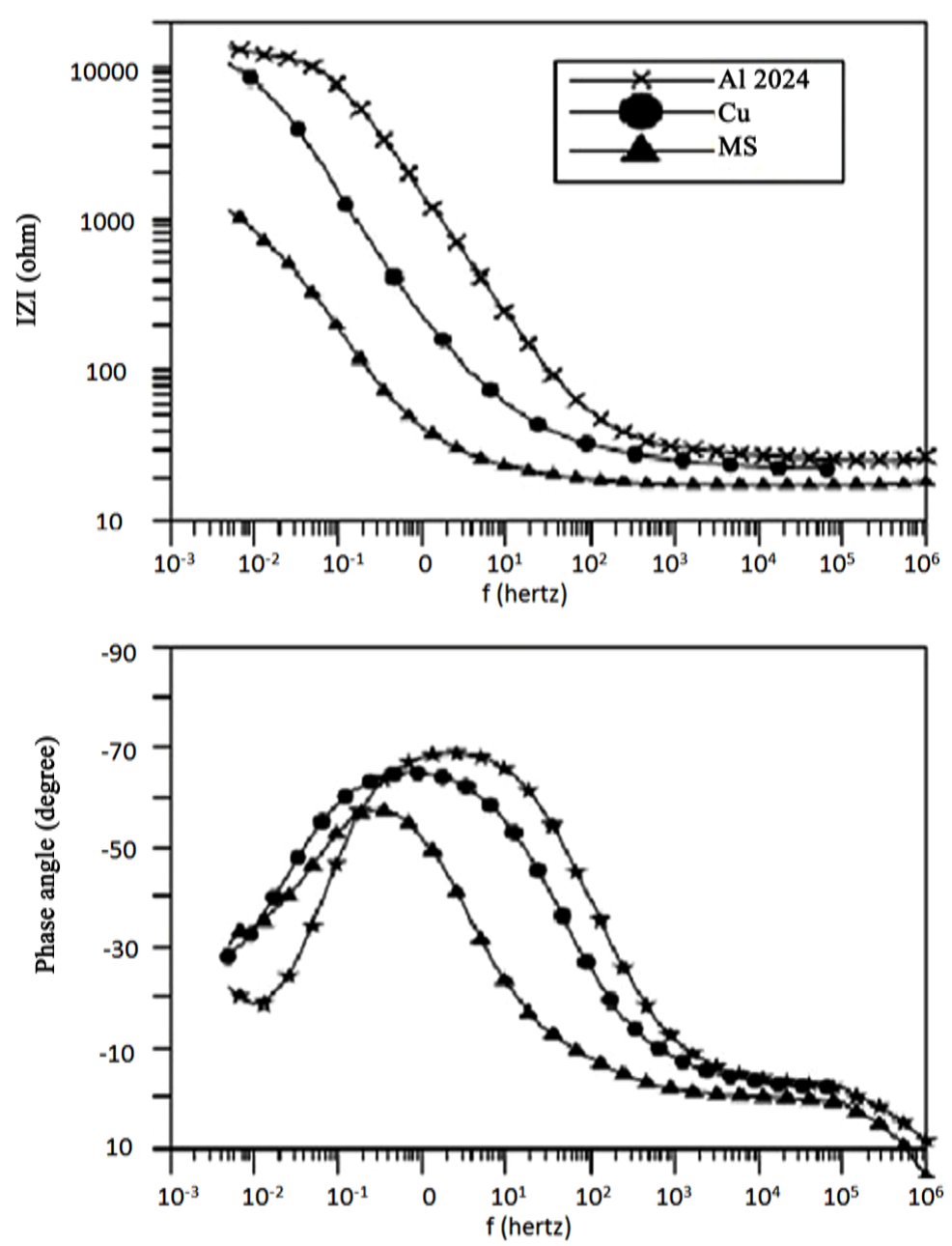

Figure 5. Bode plots for $\mathrm{Al}, \mathrm{Cu}$ and $\mathrm{MS}$ exposed to $\mathrm{NaCl}$ for 12 days.

Figure 6 shows the experimental and fitted impedance data for copper exposed to $3 \% \mathrm{NaCl}$ for 1 day. The experimental data were fitted using the Randless circuit [13]. Excellent agreement between the fitted and experimental data was obtained Figure 7. Comparing Zn with impedance resistance Zp showed a general agreement for the tested alloys (Figure 7).

The experimental EN data were transformed from the time domain into the frequency domain by fast Fourier transform (FFT) [17]. Power spectral density (PSD) plots were obtained for both potential and current fluctuations, respectively. The spectral noise plot $\left(Z_{s n}(f)\right)$ can be estimated according to [18] [19]:

$$
Z_{\text {sn }}(f)=\left|\frac{V_{F F T}(f)}{I_{F F T}(f)}\right|=\left(\frac{V_{P S D}(f)}{I_{P S D}(f)}\right)^{1 / 2}
$$

where $V_{F F T}$ and $I_{F F T}$ are the Fast Fourier Transformer functions of the potential and current noise, respectively, and $V_{P S D}$ and $I_{P S D}$ are the corresponding power spectral density (PSD) plots. SV and SI are the slopes of the PSD plots of potential and current noise, respectively. The spectral noise resistance $\left(Z_{s n}\right)$ could be defined as the DC limit of $Z_{s n}(f)$ plots, in the same way like $Z p$, which is defined as the limit of impedance when the frequency tends to zero [20]. Figure 8(a) and Figure 8(b) show the VPSD plots and IPSD plots obtained after FFT of potential and current fluctuations, respectively for MS exposed to $\mathrm{NaCl}$ before and after removing the DC trend. It is clear that the presence of trend greatly affect the amplitude and the shape of PSD plots. In this case, higher amplitude in both current and potential PSD plots was observed for the raw data than for the de-trended data. Consequently, $Z_{s n}$ plot for raw data will be higher in amplitude than the de-trended one (Figure 8(c)). In 

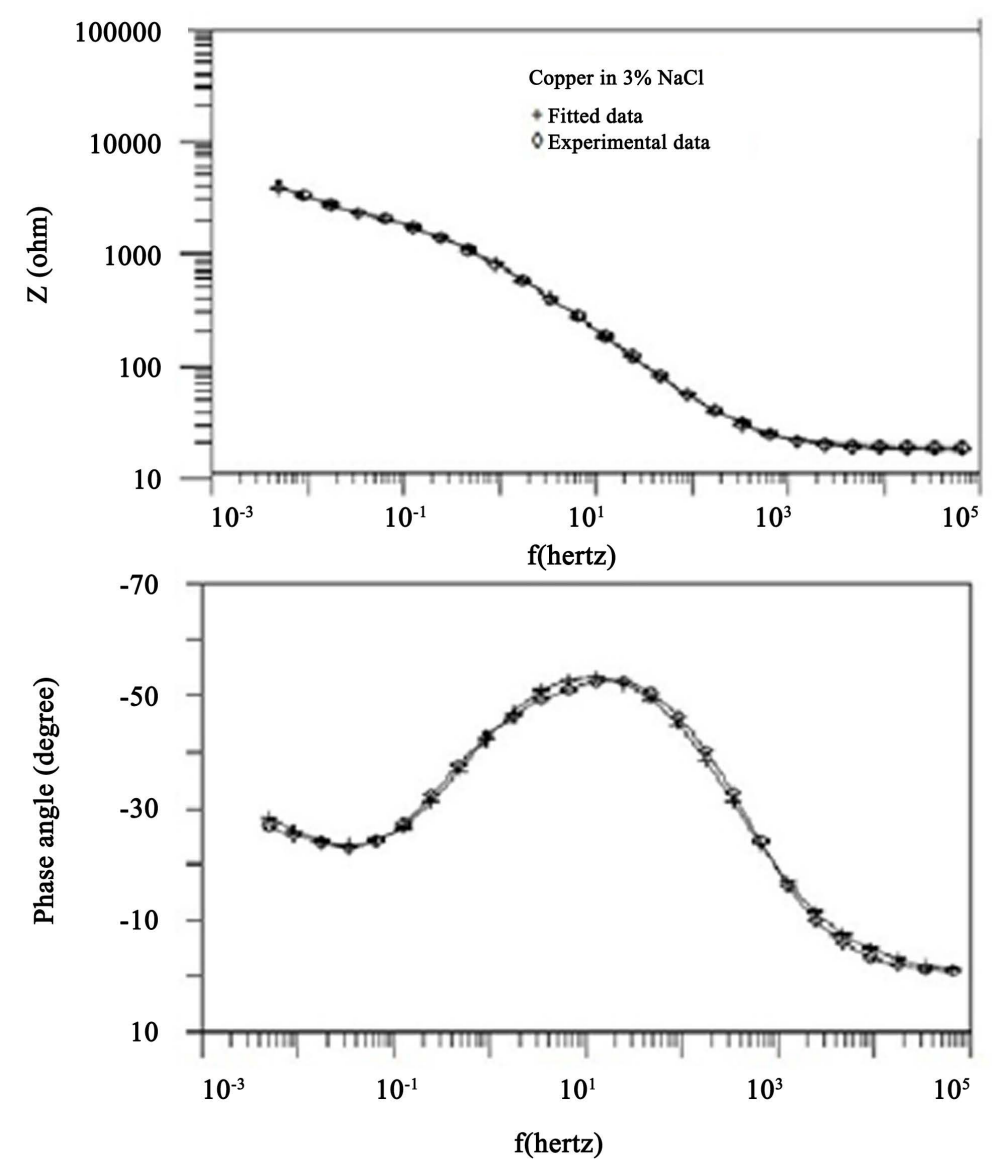

Figure 6. Comparison between experimental and fitted data for copper exposed to $\mathrm{NaCl}$ for 1 day.

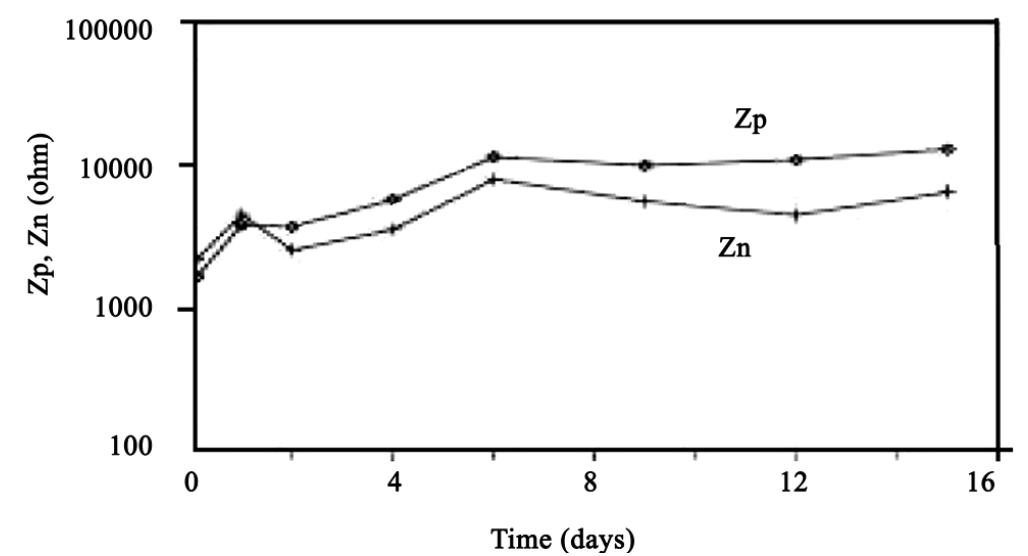

Figure 7. Time dependence of $\mathrm{Zp}$ and $\mathrm{Zn}$ for copper exposed to $\mathrm{NaCl}$.

agreement with our previous results, these results also show how the DC trend greatly affects noise data calculated in the frequency domain [13]-[16] [21] [22].

Figure 9(a) shows a comparison between the impedance and spectral noise plots of copper exposed to $\mathrm{NaCl}$ for 1 and $12 \mathrm{~d}$, respectively. No good agreement was observed between the spectral noise plots and the impedance plots. On the other hand a good agreement was obtained between the impedance and spectral noise plots for $\mathrm{Al} 2024$ and MS 1018 exposed to $\mathrm{NaCl}$ for 9 days (Figure 9(b)). 


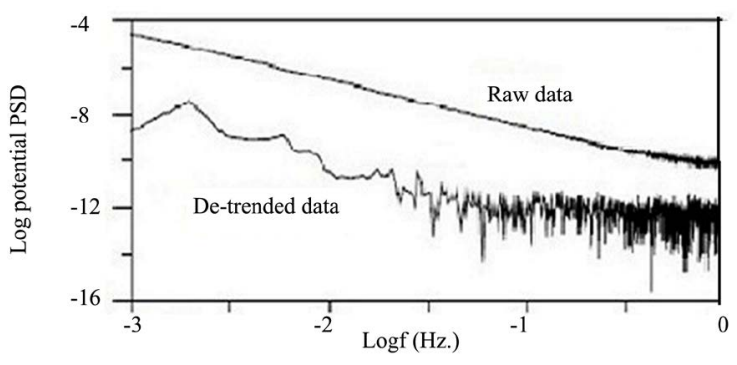

(a)

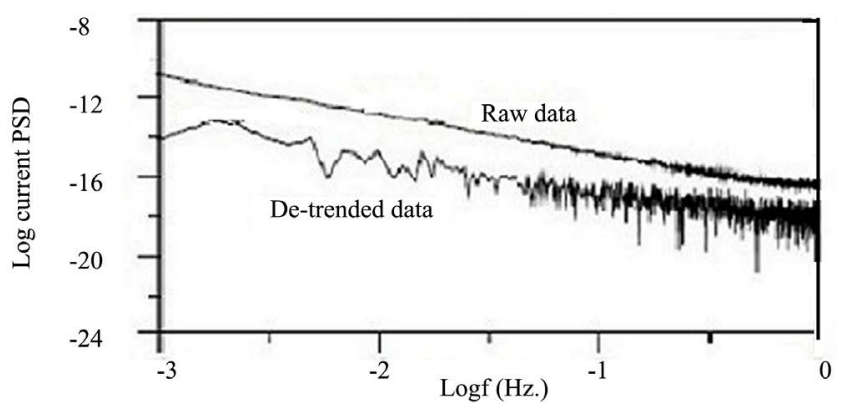

(b)

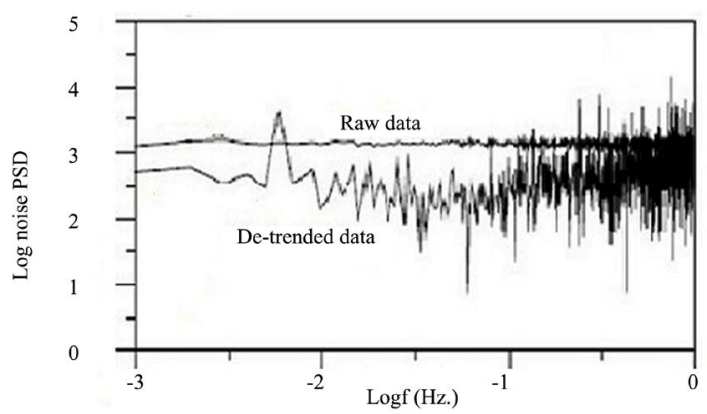

(c)

Figure 8. PSDs plots for potential (a), current (b) and spectral noise plot (c) for MS exposed to NaCl before and after trend removal.

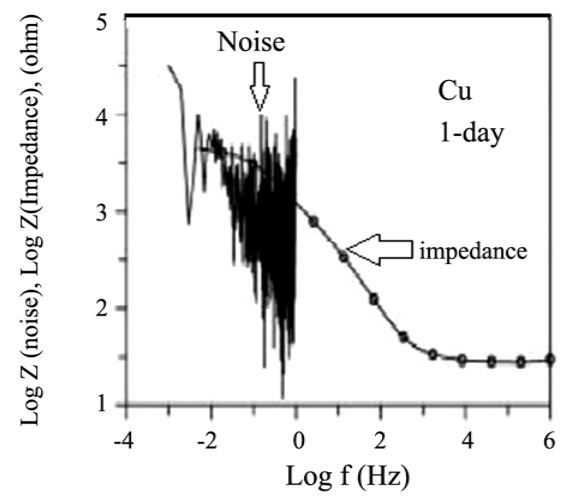

(a)

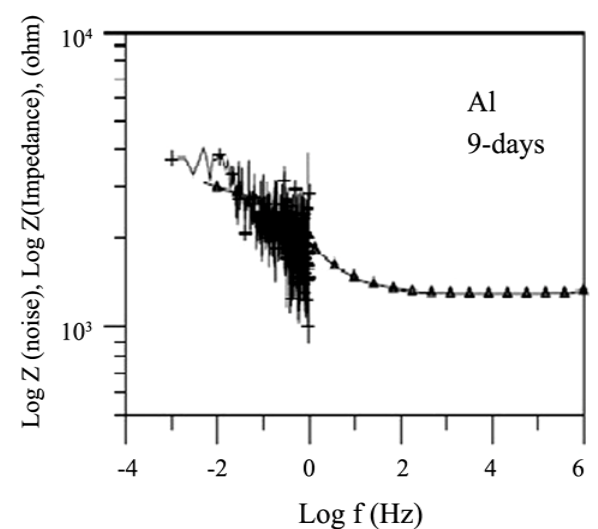

(c)

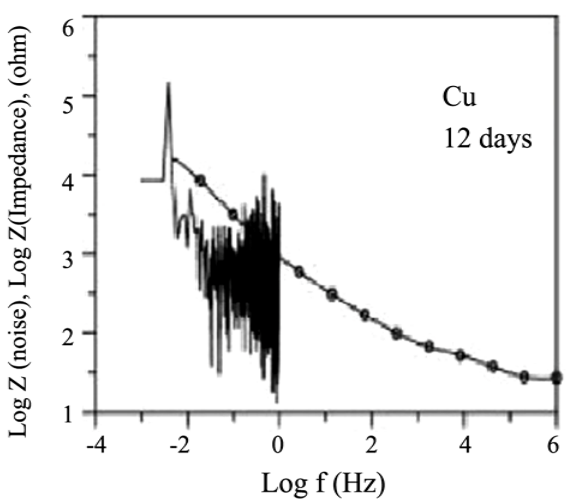

(b)

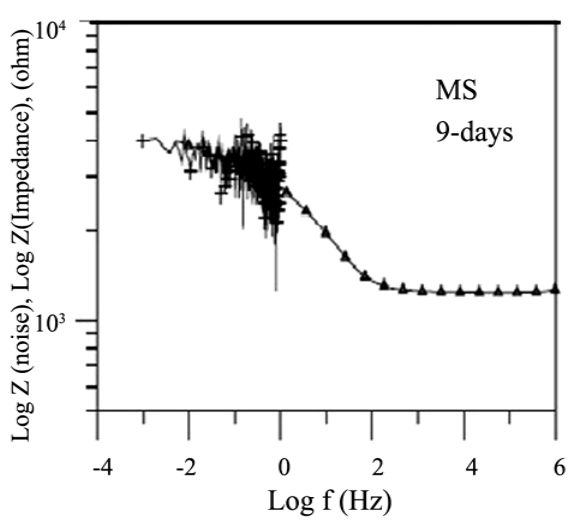

(d)

Figure 9. Impedance and spectral noise plots comparison after trend removal for $\mathrm{Cu}(\mathrm{a}$ and $\mathrm{b})$, $\mathrm{Al})$ (c) and MS (d). 


\section{Summary and Conclusions}

In this paper, the corrosion behavior of MS 1018, Al 2024 and pure copper 99.9\% have been investigated using EN and EIS techniques. The EN data was affected by drift during the measurement period, which was removed using polynomial trend removal method. Zn was calculated after analysis of EN data in the time domain and showed an agreement with Zp obtained from EIS analysis. The analysis of EN data in the frequency domain are in good agreement with those obtained by EIS. Analysis of EN data demonstrated that EN was successfully able to compare between different alloys as indicated by the difference of $\mathrm{Zn}$ values obtained for $\mathrm{Al}$, $\mathrm{Cu}$ and $\mathrm{MS}$. Analysis of ENA data did not reveal significant changes in the distribution of data that remained normal in all cases as indicated by the skewness and kurtosis data. Increases of $\mathrm{Zn}$ and the spectral noise impedance were ob-served for $\mathrm{Al} 2024$ and mid steel, while for copper the spectral noise impedance did not agree with the electrochemical impedance. LI obtained for the three metals exposed to $\mathrm{NaCl}$ were close to zero for Al 2024, copper and mild steel. It was concluded that EN data did not provide mechanistic information for the material/solutions system studied.

\section{References}

[1] Iverson, W.P. (1968) Transient Voltage Changes Produced in Corroding Metals and Alloys. Journal of the Electrochemical Society, 115, 617-618. http://dx.doi.org/10.1149/1.2411362

[2] Tyagai, V.A. (1971) Faradic Noise of Complex Electrochemical Reactions. Electrochimica Acta, 16, 1647-1654. http://dx.doi.org/10.1016/0013-4686(71)85075-2

[3] Tyagai, V.A. (1974) Noise in Electrochemical Systems. Elektrokhmiya, 10, 3.

[4] Eden, D.A., Hladky, K., John, D.G. and Dawson, J.L. (1986) Electrochemical Noise-Simultaneous Monitoring of Potential and Current Noise Signals from Corroding Electrodes. Corrosion/86, Paper No. 274. NACE, Houston.

[5] Aballe, A., Bautista, A., Bertocci, U. and Huet, F. (2000) The Measurement of Noise Resistance for Corrosion Application. Corrosion/2000, Paper No. 424. NACE, Houston.

[6] Bertocci, U., Gabrielli, C., Huet, F. and Keddam, M. (1997) Noise Resistance Applied to Corrosion Measurements. Journal of the Electrochemical Society, 144, 31-37. http://dx.doi.org/10.1149/1.1837361

[7] Mansfeld, F. and Xiao, X. (1997) The Frequency Dependence of the Noise Resistance for Polymer Coated Metals. Electrochemical Society, 144, 2068-2071. http://dx.doi.org/10.1149/1.1837743

[8] Mills, D.J., Bierwagen, G.P., Skerry, B.S. and Tallman, D. (1995) Investigation of Anticorrosive Coatings by the EN Method. Mater Performance, 34, 33.

[9] Eden, D.A. and Rothwell, A.N. (1992) Electrochemical Noise Data Analysis Interpretation and Presentation. Corrosion/92, Paper No. 292, NACE, Huoston.

[10] Kearns, J.R., Scully, J.R., Roberge, P.R., Reichert, D.L. and Dawson, J.L. (1996) Electrochemical Noise Measurements for Corrosion Application. ASTM STP 1227, American Society for Testing and Materials, West Conshohocken.

[11] Earthman, J.C., Arps, P., Farhangrazi, Z.S., Trandem, K. and Wood, T. (2001) Field Sidestream Investigation of Corrosion Control Using Regenerative Biofilms (CCURB). Paper No. 1271, Corrosion/2001, NACE, Houston.

[12] Mansfeld, F. and Sun, Z. (1999) Technical Note: Localization Index Obtained from Electrochemical Noise Analysis. Corrosion, 55, 915-918. http://dx.doi.org/10.5006/1.3283926

[13] Mansfeld, F., Sun, Z., Hsu, C.H. and Nagiub, A. (2001) Concerning Trend Removal in Electrochemical Noise Measurements. Corrosion Science, 43, 341-352. http://dx.doi.org/10.1016/S0010-938X(00)00064-0

[14] Nagiub, A. and Mansfeld, F. (2001) Evaluation of Corrosion Inhibition of Brass in Chloride Media Using EIS and ENA. Corrosion Science, 43, 2147-2171. http://dx.doi.org/10.1016/S0010-938X(01)00079-8

[15] Nagiub, A. and Mansfeld, F. (2001) Microbiologically Influenced Corrosion Inhibition (MICI) Due to Bacterial Contamination. Materials and Corrosion, 52, 817-826. http://dx.doi.org/10.1002/1521-4176(200111)52:11<817::AID-MACO817>3.0.CO;2-1

[16] Nagiub, A. and Mansfeld, F. (2002) Evaluation of Microbiologically Influenced Corrosion Inhibition (MICI) with EIS and ENA. Electrochimica Acta, 37, 2319.

[17] Oppenheim, A.V. and Schafer, R.W. (1989) Discrete-Time Signal Processing. Prentice-Hall, Inc., Englewood Cliffs.

[18] Mansfeld, F., Xiao, H., Han, L.T. and. Lee, C.C. (1997) Electrochemical Impedance and Noise Data for Polymer Coated Steel Exposed at Remote Marine Test Site. Progress in Organic Coatings, 30, 89-100.

http://dx.doi.org/10.1016/S0300-9440(96)00675-3 
[19] Mansfeld, F., Han, L.T., Lee, C.C., Chen, C., Zhang, G. and Xiao, H. (1997) Analysis of Electrochemical Impedance and Noise Data for Polymer Coated Metals. Corrosion Science, 39, 255-279. http://dx.doi.org/10.1016/S0010-938X(97)83346-X

[20] Xiao, H., Han, L.T., Lee, C.C. and Mansfeld, F. (1997) Collection of Electrochemical Impedance and Noise Data for Polymer Coated Steel from Remote Test Sites. Corrosion, 53, 412-422. http://dx.doi.org/10.5006/1.3280484

[21] Nagiub, A.M. (2006) Electrochemical Noise Analysis and Electrochemical Impedance Spectroscopy for Pure Copper in Chloride Media. Chinese Journal of Chemistry, 24, 1. http://dx.doi.org/10.1002/cjoc.200690047

[22] Nagiub, A.M. (2013) Electrochemical Noise Analysis for Different Green Corrosion Inhibitors for Mild Steel Exposed to $0.5 \mathrm{H}_{2} \mathrm{SO}_{4}$, Corrosion/2013, Paper No. 2458, NACE, Houston. 
Scientific Research Publishing (SCIRP) is one of the largest Open Access journal publishers. It is currently publishing more than 200 open access, online, peer-reviewed journals covering a wide range of academic disciplines. SCIRP serves the worldwide academic communities and contributes to the progress and application of science with its publication.

Other selected journals from SCIRP are listed as below. Submit your manuscript to us via either submit@scirp.org or Online Submission Portal.
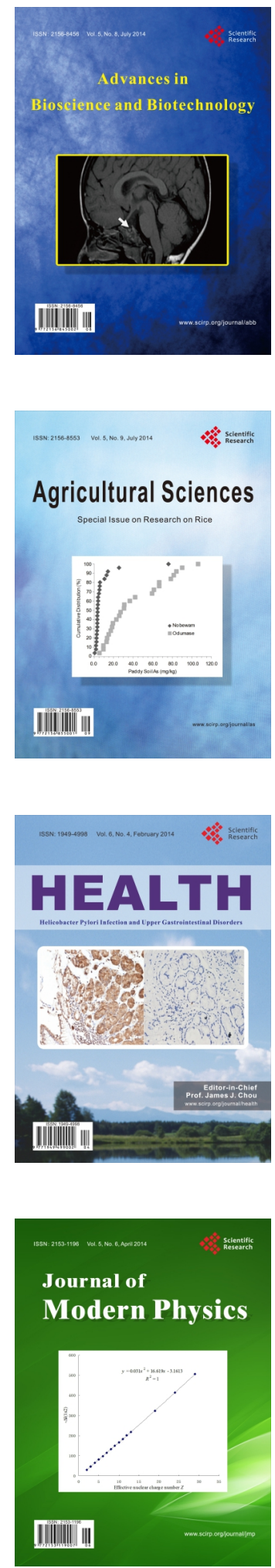
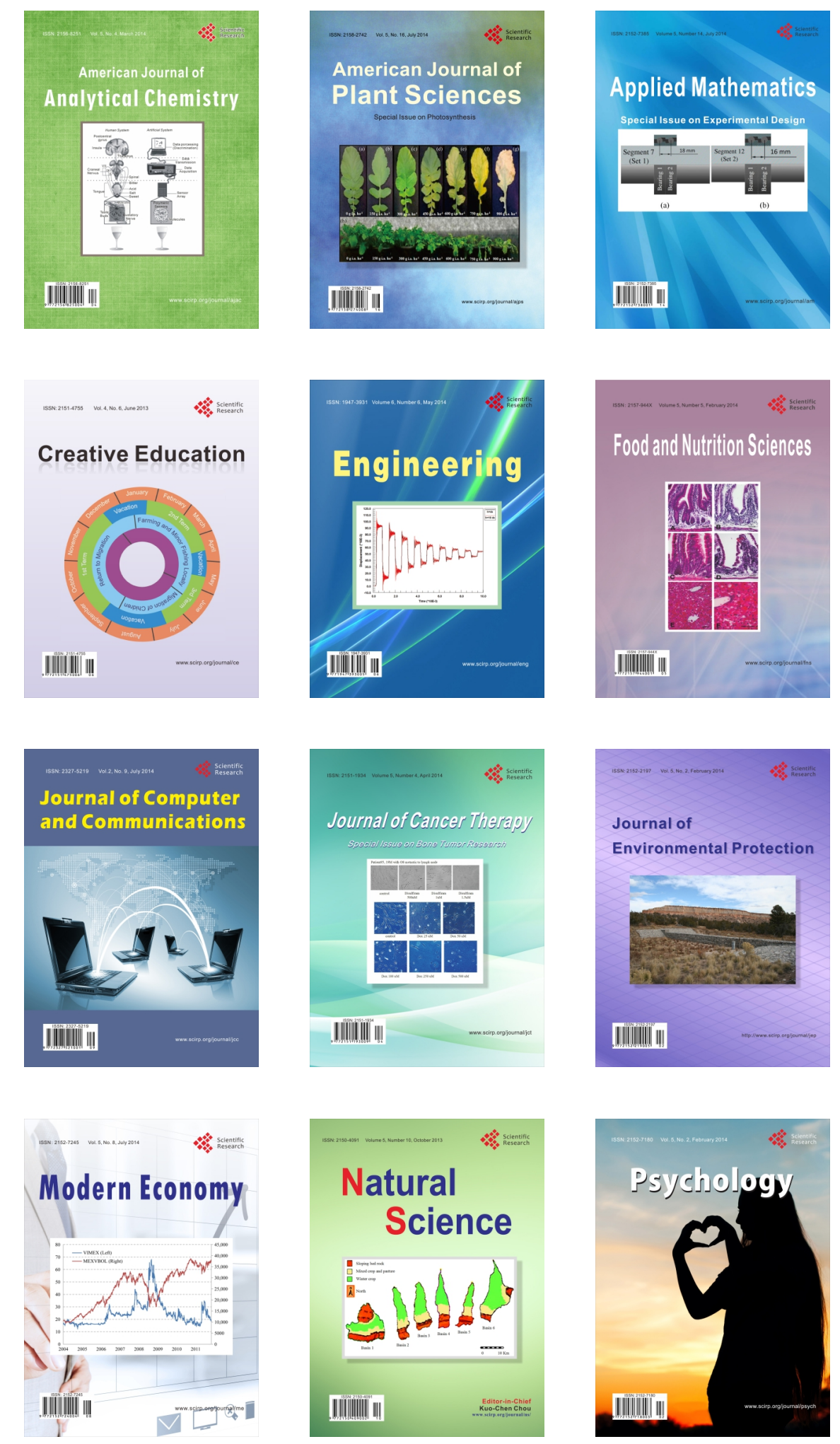